\title{
Prevalence, Trends and Associated Socio-Economic Factors of Obesity in South Asia
}

\author{
Ranil Jayawardena ${ }^{a, b} \quad$ Nuala M. Byrne ${ }^{a}$ Mario J. Soares ${ }^{c}$ \\ Prasad Katulanda ${ }^{b}$ Andrew P. Hills ${ }^{d}$ \\ ${ }^{a}$ Institute of Health and Biomedical Innovation, Queensland University of Technology, \\ Brisbane, Queensland, Australia, ${ }^{b}$ Diabetes Research Unit, Faculty of Medicine, University \\ of Colombo, Colombo, Sri Lanka, 'Curtin Health Innovation Research Institute, School of \\ Public Health, Faculty of Health Sciences, Curtin University, Perth, Western Australia, dMater \\ Mother's Hospital, Mater Medical Research Institute and Griffith Health Institute, Griffith \\ University, Brisbane, Queensland, Australia
}

\author{
Key Words \\ Obesity · Socio-economic factors · Prevalence · Trend · South Asia
}

\begin{abstract}
Aim: Worldwide obesity levels have increased unprecedentedly over the past couple of decades. Although the prevalence, trends and associated socio-economic factors of the condition have been extensively reported in Western populations, less is known regarding South Asian populations. Methods: A review of articles using Medline with combinations of the MeSH terms: 'Obesity', 'Overweight' and 'Abdominal Obesity' limiting to epidemiology and South Asian countries. Results: Despite methodological heterogeneity and variation according to country, area of residence and gender, the most recent nationally representative and large regional data demonstrates that without any doubt there is a epidemic of obesity, overweight and abdominal obesity in South Asian countries. Prevalence estimates of overweight and obesity (based on Asian cut-offs: overweight $\geq 23 \mathrm{~kg} / \mathrm{m}^{2}$, obesity $\geq 25 \mathrm{~kg} / \mathrm{m}^{2}$ ) ranged from $3.5 \%$ in rural Bangladesh to over $65 \%$ in the Maldives. Abdominal obesity was more prevalent than general obesity in both sexes in this ethnic group. Countries with the lowest prevalence had the highest upward trend of obesity. Socio-economic factors associated with greater obesity in the region included female gender, middle age, urban residence, higher educational and economic status. Conclusion: South Asia is significantly affected by the obesity epidemic. Collaborative public health interventions to reverse these trends need to be mindful of many socio-economic constraints in order to provide long-term solutions.
\end{abstract}


Jayawardena et al.: Prevalence, Trends and Associated Socio-Economic Factors of Obesity in South Asia

\section{Introduction}

Worldwide obesity levels have increased unprecedentedly over the past couple of decades. Indeed, according to the World Health Organization's (WHO) recent global estimates, over one billion and nearly 300 million adults are overweight and obese respectively [1]. In many affluent countries, obesity has reached epidemic levels and is associated with non-communicable diseases (NCDs) including diabetes, hypertension, dyslipidaemia and coronary heart disease, all major public health issues [2]. In affluent countries, socio-economic status and education level are negatively associated with the prevalence of obesity, a situation which contrasts to that in South Asia [3]. Traditionally, infectious diseases [4] and under-nutrition [5] were considered major health problems in South Asia, and little attention was paid to obesity by healthcare workers, policy makers or researchers. However, with the rapid emergence of the obesity epidemic in South Asian countries and an increasing body of evidence that people originating from the Indian sub-continent have a high risk for NCDs including diabetes mellitus type 2, coronary heart disease and stroke compared to Europeans [6], greater attention is being paid. Alarmingly, South Asia has the highest number of patients with diabetes worldwide, and $50 \%$ of the adult disease burden in South Asia is attributable to NCDs [7].

It is estimated that the total population living in South Asia now exceeds 1.56 billion with India (2nd), Pakistan (6th) and Bangladesh (7th) among the ten most populated countries in the world [8]. Moreover, people who originated from the Indian sub-continent are also widespread in most countries of the world, predominantly in affluent nations. The disease burden in South Asians is invariably a high priority as a global health issue. Although there have been a few in-depth reviews on obesity and associated disease in Asia [6, 9], none has discussed obesity prevalence and trends for individual countries in the region. Therefore, the main aim of this study was to discuss the prevalence of overweight and obesity among the adult population from individual countries in South Asia using the most recent representative evidence. Associated aims were to plot obesity trends over time across the last few decades and to identify and discuss the socio-economic factors associated with obesity in the region.

\section{Material and Methods}

In this review, South Asians are defined as people living in the Indian subcontinent which consists of the following countries: India, Pakistan, Sri Lanka, Bangladesh, Nepal, Bhutan and the Maldives. Countries from the Far East (Japan, China etc.) and South East Asia (Malaysia, Thailand, Singapore etc.) were excluded [10]. There is an active collaboration and mutual assistance (South Asian Association for Regional Cooperation SAARC) among these countries in economic, social, cultural, technical and scientific fields [11]. Despite the existence of considerable heterogeneity among the inhabitants of South Asia, there are several similarities in the biological and socio-cultural aspects of the people from this region that allows this group to be considered as a single unit for the purpose of examination of health issues [12].

Overweight and obesity prevalence data among adults in the South Asian countries studied were obtained by searching Medline with combinations of the MeSH terms: 'Obesity' and 'Overweight' as separate main key words for papers published in English between January 1, 1980 and December 31, 2011. Secondly, each key word was divided into subheadings and 'Epidemiology/EP' included for searching with main key words. Thirdly, the conjunction of the above results was narrowed down by adding the name of each country (India, Pakistan, Bangladesh, Sri Lanka, Nepal, Bhutan and Maldives) as key words. A manual search was performed for future evidence using the reference lists of selected articles, and corresponding authors were contacted to obtain additional data. Furthermore, relevant governmental health and WHO websites were browsed.

The primary search was focused on research investigating the prevalence of overweight, obesity or abdominal obesity in each country. Priority was given to larger $(n>2,000)$, nationally representative samples. 
Jayawardena et al.: Prevalence, Trends and Associated Socio-Economic Factors of Obesity in South Asia

Studies done in clinical settings and those performed in patients with special medical conditions or limited to special groups (e.g. doctors) or age category (e.g. age > 65 years) were excluded. Studies of South Asians living in the non-South Asian countries were excluded.

Initial screening of articles was carried out using abstracts. Unless it was clear from the abstract that this study met the inclusion criteria for the review, the article was rejected. For prevalence data, the most recent, well-designed and nationally representative or large studies were included.

Trends were plotted by available prevalence data from each country according to gender.

\section{Results}

National prevalence of obesity in individual countries (table 1)

No data were found from Bhutan. Limited nationwide surveys were found in the region, and most recent studies were completed between 2004 and 2006. The STEPS survey in the Maldives [13] and the SLDC study [14] in Sri Lanka reported on prevalence of overweight, obesity and abdominal obesity using similar anthropometric cut-offs and in a similar period of time. The study in the Maldives reported the highest prevalence of overweight, obesity and abdominal obesity in the region with $60.8 \%$ of males and $65.5 \%$ of females being overweight and obese. The overall prevalence of obesity and abdominal obesity was $43.5 \%$ and $40.0 \%$, respectively, with half the women being obese (48.1\%) and abdominally obese (54.1\%) [13]. Sharma et al. [15] recently reported a very high prevalence of overweight among both Nepalese men (59.1\%) and women (61.8\%); however, they have reported lower BMI cut-offs to define overweight $\left(\geq 22 \mathrm{~kg} / \mathrm{m}^{2}\right)$. As per the WHO definition for overweight in Asian adults $\left(\mathrm{BMI} \geq 23 \mathrm{~kg} / \mathrm{m}^{2}\right.$ ) a quarter of Sri Lankan adults (M: 22.6\%, F: 28.0\%) were overweight [14]. In Bangladesh, a large survey undertaken on reproductive age woman reported levels of overweight of $9.6 \%$ and $18.9 \%$ among rural and poor urban areas, respectively [16]. No nationally representative data are available on men; however, data from four sites in Bangladesh showed that around $10 \%$ of men had a BMI above $25 \mathrm{~kg} / \mathrm{m}^{2}$ [17]. Results from the National Health Survey of Pakistan showed a high prevalence of overweight (M: $22.0 \% \mathrm{~F}$ : $27.9 \%$ ) and obesity (M: $12.5 \%$ F: 18.6) in the early 1990s [18]. Moreover, the authors noted a 2.5 times greater prevalence of obesity among urban than among rural residents [18]. In 2007, a study on a rural population showed $19.5 \%$ and $24.7 \%$ obesity levels (BMI $\geq 25$ $\mathrm{kg} / \mathrm{m}^{2}$ ) in men and women, respectively [19].

Prevalence data in India is more complex. For example, the Indian National Family Health Survey- 3 reported prevalence data on obesity in a large sample $(n=111,781)$ across 26 states [20] with moderate levels of obesity; $9.3 \%$ for men and $12.6 \%$ for women. In contrast, Deepa et al. [21] reported $46.1 \%$ and $50.2 \%$ overweight and obesity, respectively, in a study in South India. In addition, using the Asian waist circumference cut-offs, the same study reported that $35.1 \%$ of men and $56.2 \%$ of women had abdominal obesity, a higher level than in any other national values for countries in the region [21]. Astudy undertaken in six different geographical locations in India (East, South, North, West/Central) showed different levels of obesity according to rural or urban residence. In urban areas, obesity levels were as high as $30.7 \%$ in men and $38.8 \%$ in women; whilst in rural areas values were $9.4 \%$ in men and $14.1 \%$ in women. In contrast, obesity levels in slums were intermediate, $16.7 \%$ and $26.1 \%$, for men and women, respectively [22]. Similar patterns were reported for abdominal obesity.

\section{Time Trends in the Prevalence of Obesity}

No well-designed nationally representative studies were found for the Maldives or Bhutan. Limited time series information is available for other countries. Prevalence data were plotted in the time trends according to the methodological similarities of the studies. BMI $\geq$ 
Jayawardena et al.: Prevalence, Trends and Associated Socio-Economic Factors of Obesity in South Asia

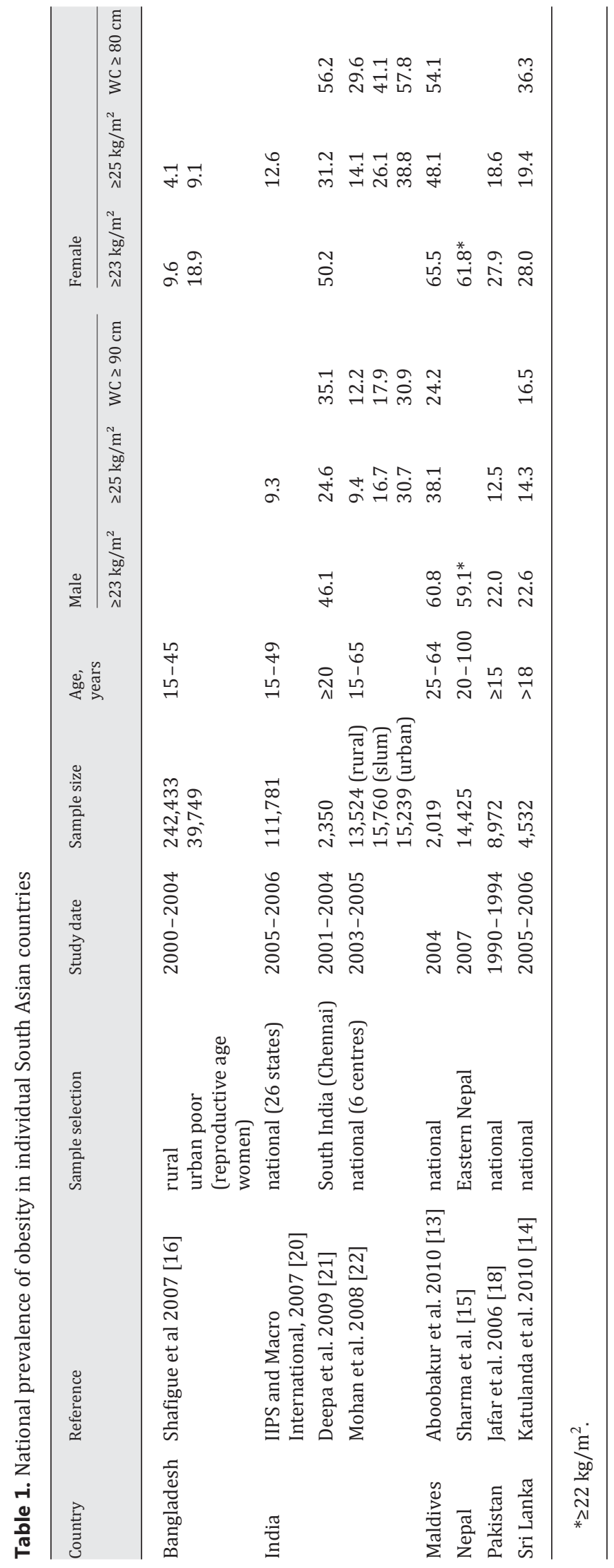


Fig. 1. a Trends in the prevalence of obesity (BMI $\geq 25 \mathrm{~kg} / \mathrm{m}^{2}$ ) in Sri Lanka, India and Pakistan in adult males. $\mathbf{b}$ Trends in the prevalence of obesity (BMI $\geq 25 \mathrm{~kg} / \mathrm{m}^{2}$ ) in Sri Lanka, Bangladesh, Nepal, India and Pakistan in adult females.

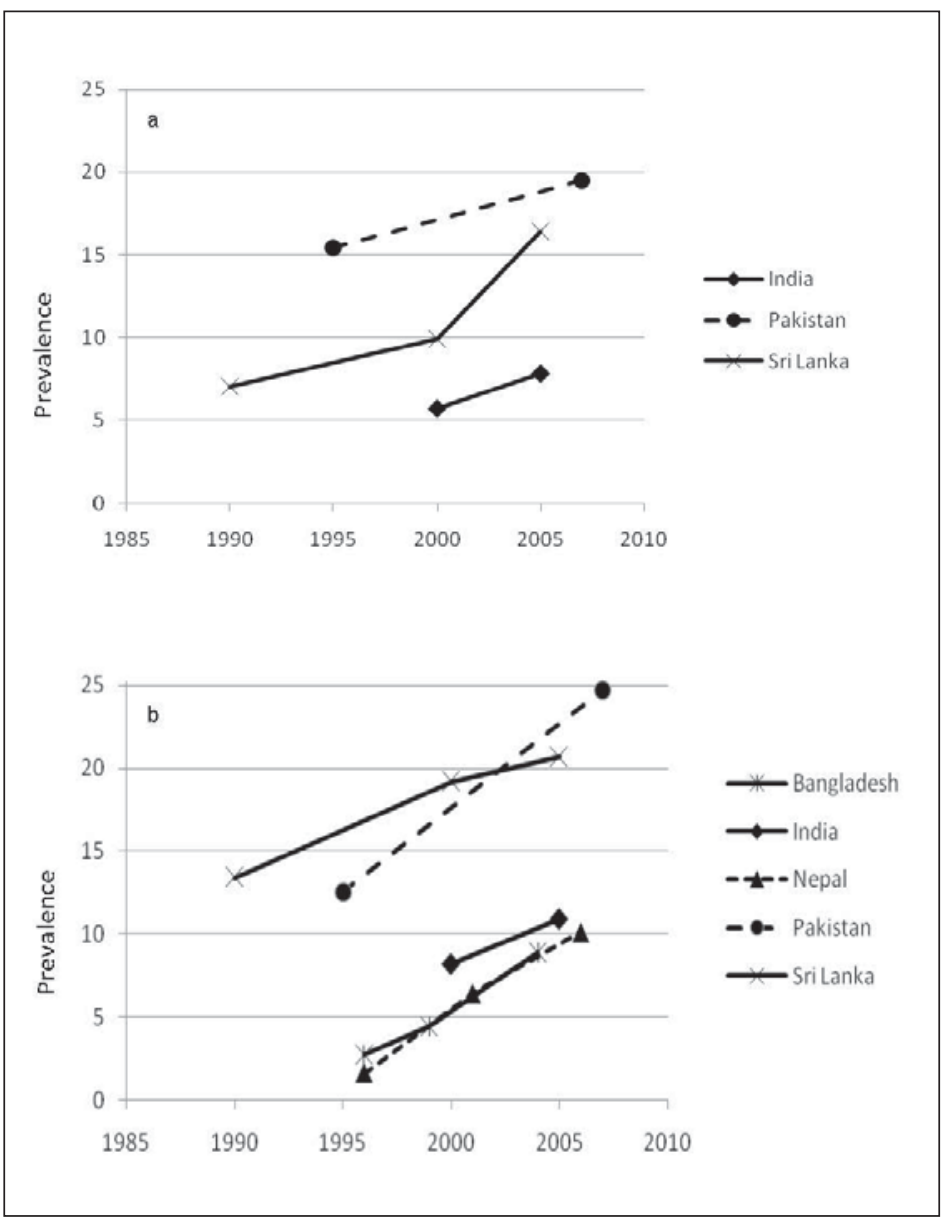

$25 \mathrm{~kg} / \mathrm{m}^{2}$ was used as it was the commonly used cut-off for most of the recent and earlier studies, which allows conclusions to be drawn on weight trends. An obvious upward trend was seen in all countries in the region (fig. 1). In Sri Lanka, the age-adjusted prevalence of obesity in both men and women increased from $7.0 \%$ (male) and $13.4 \%$ (female) in 1990 to 9.9\% (male) and 19.2\% (female) in 2000. A further increase in obesity can be seen in 2005 (M: 16.4\%; F: 20.7\%) [14, 23, 24]. As obesity data in 1990 and 2000 were taken from an urban area (Colombo, Maharagama) [23, 24], the comparison in 2005 was taken from obesity prevalence in the urban area [14]. Obesity prevalence in males may have been under-reported in 2000 and 1995 as the authors used a BMI level of $>27 \mathrm{~kg} / \mathrm{m}^{2}$ as the obesity cut-off for males but $>25 \mathrm{~kg} / \mathrm{m}^{2}$ for female counterparts $[23,24]$.

Although the absolute prevalence of overweight and obesity in Nepal and Bangladesh are currently the lowest in the region, the relative increases over the last two decades are the highest in the region. A series of national or regional obesity datasets on ever-married, nonpregnant women in Bangladesh showed a clear positive trend in both urban and rural populations [25]. In 1996, only $2.7 \%$ of women had a BMI $>25 \mathrm{~kg} / \mathrm{m}^{2}$, and within 3 years the proportion had reached 4.4\%. By 2004, a value three times higher than in 1996 (8.9\%) [25] was found. In Nepal, the prevalence of obesity among women was $1.6 \%$ in 1996 which increased to $6.4 \%$ in 2001 and then to $10.1 \%$ in 2006. This level of change over such a short period is the highest in the region. Despite the absence of trend data on the prevalence of overweight and obesity in Pakistan, Shah et al. [19] conducted two independent cross- 
Jayawardena et al.: Prevalence, Trends and Associated Socio-Economic Factors of Obesity in South Asia

Table 2. Socio-economic factors associated with the prevalence of obesity in the South Asian region

\begin{tabular}{lll}
\hline Positive factor & Positive or negative factors & Negative factors \\
\hline Female gender [14, 29-31] & sub-ethnicity [18] & smoking [15, 18, 32] \\
Age [14-16, 21, 28-29, 33-35] & region of the country [28-29, 36] & male [18] \\
Urban residence [14,15, 18,29-34] & religion [32, 33] & tuberculosis [32] \\
High education level [14,18,32-33,35, 37] & caste [32, 33] & rural [35] \\
Socio-economic index [14, 15, 17, 18, 29-33, 35] & marital status [32, 38] & unskilled [35] \\
Physical inactivity [14, 28, 31, 38] & & \\
Dietary habits [18,31,38] & & \\
Skilled workers [37] & & \\
Low birth weight [39] & & \\
\hline
\end{tabular}

sectional population surveys in rural Pakistan in 1995 and 2007. The age-adjusted prevalence of overweight and obesity (BMI $>25 \mathrm{~kg} / \mathrm{m}^{2}$ ) increased from $13.9 \%$ in 1995 to $19.4 \%$ in 2007. In men, the increase was from $15.4 \%$ to $19.5 \%$ and in women from $12.5 \%$ to $24.7 \%$.

There are a few nationwide and several regional studies in India over the last few decades; however, there is no series of national level study to cover all parts of the country. This may be due to the size of the population and lack of resources. The National Nutrition Monitoring Bureau of India conducted a couple of large studies in nine rural states in India in 2000 [26] and 2005 [27]. The obesity prevalence was $5.7 \%$ and $8.2 \%$ in men and women, respectively, in 2000 , which increased to $7.8 \%$ and $10.9 \%$ in 2005 . Although values are low in both circumstances, obesity levels had increased by $37 \%$ and $32 \%$ in both men and women, respectively, over the 5-year period. Some regional studies reported very high levels of obesity, in particular in urban areas $[21,22,28]$. However, in India, there is a considerable disparity in the prevalence and in the time trends of the prevalence of obesity in different geographical regions and residents in different areas of the same geographical location. A recent review noted the complexity of over- and under-nutrition problems in India [29].

Socio-Economic Factors Associated with Prevalence of Obesity in the South Asian Region

Several similar socio-economic factors are associated with the increase in obesity in the region. Female sex, middle age, urban residence, higher educational and economic status, physical inactivity and some dietary habits (table 2) were positively associated with a high prevalence of obesity. Yajnik [30] suspects the obesity epidemic may be associated with low birth weight in Indian babies. In contrast to the above factors, smoking and tuberculosis were negatively associated with the obesity prevalence [31]. Many studies have shown that smokers have lower body weights than their non-smoking counterparts; in contrast a study by Gosh et al .[32] showed that both ex smoking and never smoking decreased the waist-height ratio (WHR) significantly, whereas smoking increased WHR. There was considerable variation in the prevalence of obesity according to sub-ethnicity, region of the country, religion, caste and marital status for women.

\section{Discussion}

Historically, under-nutrition and deficiencies have been considered the major health issues in South Asian countries. Even in the most recent literature, the region is considered to have one of the lowest levels of excess body weight [33]. However, this information alone 
Jayawardena et al.: Prevalence, Trends and Associated Socio-Economic Factors of Obesity in South Asia

is misleading because it does not examine the prevalence, trends and associated factors of obesity in the region. To our knowledge, this is the first systematic review to discuss prevalence trends and associated socio-economic factors of obesity in South Asian countries. Despite the very limited recent nationally representative obesity prevalence data from countries in the Indian subcontinent, our results show that the prevalence of obesity has reached epidemic levels in almost every country and is more serious in urban areas. Considering the size of the population of the region, the number of people who are affected by overweight and obesity represents numbers well above those in most developed countries. These studies have mainly used Asian BMI and waist circumference cut-offs (overweight $\geq 23 \mathrm{~kg} / \mathrm{m}^{2}$; obesity $\geq 25 \mathrm{~kg} / \mathrm{m}^{2}$ ) to define overweight, obesity and abdominal obesity (waist circumference: $\mathrm{M} \geq 90 \mathrm{~cm} ; \mathrm{F} \geq 80 \mathrm{~cm}$ ) [34, 35]. However, a growing body of evidence shows that BMI a $\geq 23 \mathrm{~kg} / \mathrm{m}^{2}$ is not sensitive enough to identify the obesity-associated disease risk in South Asian populations.

\section{BMI and Waist Circumference for Obesity in South Asians}

Studies from India [36], Pakistan [18] and Sri Lanka [37] have shown that a BMI of 21 $\mathrm{kg} / \mathrm{m}^{2}$ would be the appropriate anthropometric cut-off level to identify overweight. Similarly, an Indian consensus statement also suggested a BMI of $\geq 23 \mathrm{~kg} / \mathrm{m}^{2}$ as the diagnostic cut-off value for overweight for Asian Indians [38]. Moreover, multi-ethnic studies on body composition [39] and metabolic risk factor analysis [40] showed that a BMI of $21 \mathrm{~kg} / \mathrm{m}^{2}$ is the most appropriate anthropometric cut-off for South Asian ethnic groups. Considering all factors, if obesity was defined using a lower BMI level, the prevalence of obesity in the respective countries would be substantially increased. Similarly, lower abdominal obesity cut-offs have been recommended for the South Asians [38]. However, a considerable portion of Nepalese and Bhutanese are from Chinese origin; therefore, lower anthropometric cut-offs are not equally suitable for all ethnic groups.

There has been considerable delays between data collection and the publication of findings in some countries, for instance a 16-year gap between data collection and publication date in a Pakistan national survey [18]. The rate of increase in the obesity epidemic is very fast globally, but particularly in the South Asian region. So, published reports to date may significantly underestimate the current prevalence.

\section{Socio-Economic Factors}

If environmental factors have a major role in triggering increased body weight subsequent to increased prevalence of overweight and obesity, one would expect a lower prevalence of obesity in rural areas, where people follow a traditional lifestyle. Such an urban-rural difference has been reported in almost all countries in the region. For example in Sri Lanka, the prevalence of obesity in urban areas is three times that of rural areas [14], and similar patterns have been reported in India [22] and Pakistan [18]. However, Shah et al. [19] reported that in rural Pakistan, the age-adjusted prevalence of overweight and obesity also increased from $13.9 \%$ in 1995 to $19.4 \%$ in 2007 . These results suggest that the rate of obesity might also increase in rural communities as they become more urbanised. Between 1990 and 2000, the mean BMI increased by nearly $2.5 \mathrm{~kg} / \mathrm{m}^{2}$ in rural Sri Lanka [41]. Recent economic development has improved the availability and accessibility to foods, which has occurred simultaneously with an increased quality of life in many countries. Advances in both technical and agricultural sectors have helped to reduce under-nutrition; however, the increased availability of energy-dense foods may lead to weight gain and subsequently obesity. This transition has occurred rapidly, particularly in urban regions of South Asian countries, which compares with a more gradual advancement in many affluent countries. Interestingly, most of South Asian meal consisted of excess carbohydrate-based diet [42]. 
In 2007-2008, the prevalence of obesity was $35.5 \%$ in US women [43]. Despite this being a substantial level, over a 10-year period there has not been a significant upward trend in the level of obesity in this group. In comparison, the obesity level increased 6-fold in Nepalese women between 1996 and 2006 [25]. Thus, despite the prevalence of obesity in South Asian countries being lower than that in the USA, the rate at which overweight and obesity has increased during recent decades (fig. 1) and the likelihood of further increases provides substantial grounds for concern. Obesity trend data from the Asia-Pacific region also shows low absolute values of obesity in Asian countries such as China and Japan compared to Australia but with rapid increases in the relative values during the last decades [44].

Worldwide, more females are overweight and obese compared to their male counterparts [33]. In the UK, $25 \%$ of women and $23 \%$ of men were obese in 2002 [45], while in the USA $32.2 \%$ of men and $35.5 \%$ of women suffered from obesity in $2007 / 2008$ [43]. In contrast, the gender difference in prevalence of obesity in South Asia is significantly higher; for instance, in rural Bangladesh the prevalence of obesity in women is 2.5 times higher than in males [46]. Socio-economic characteristics of the epidemic of obesity in South Asia also differ from those reported in other parts of the world. In South Asia, the highest prevalence is reached in the middle-aged (30-50 years) group, whereas in the UK obesity prevalence tends to increase progressively with age (up to 64 years) [45]. In South Asia, obesity is more common in people with high educational levels, high income or wealth and in skilled workers $[14,18,47]$. In contrast, the opposite is seen in the UK [45]. Unlike more affluent countries, a considerable proportion of South Asian populations suffer from under-nutrition [25], with people with higher education and income having relatively higher accessibility to energy and nutrient-rich foods. Interestingly, religion, caste, sub-ethnicity, region of location within the country and marital status are significant socio-economic factors leading to obesity in the region $[18,29,31,47]$. This is partly due to the above mentioned factors being strongly associated with their cultural dietary patterns and freedom of movement or physical activity levels [47]. It is very important to identify key socio-economic factors prior to initiating weight loss programmes as complex associations between obesity and socio-economic factors may make the implementation of weight loss strategies in South Asians more challenging. Moreover, corresponding to the obesity trend, South Asia faces a substantial diabetes burden [48].

\section{Limitations}

Interpretation of obesity prevalence and trends in the region is difficult due to use of various anthropometric cut-offs. For example, older studies defined overweight and obesity using global BMI cut-offs of $\geq 25 \mathrm{~kg} / \mathrm{m}^{2}$ for overweight and $\geq 30 \mathrm{~kg} / \mathrm{m}^{2}$ for obesity, whereas in recent studies ethnic-specific anthropometric cut-offs have been used. Secondly, overweight has been classified differently in the literature, with some researchers defining overweight/obesity using one value. For example, in the Maldives study, overweight is considered as a BMI of $23 \mathrm{~kg} / \mathrm{m}^{2}$ and above [13], whereas in a Bangladeshi study [49] overweight was classified using the traditional range $\left(25.0-29.9 \mathrm{~kg} / \mathrm{m}^{2}\right)$. Another limitation is that different studies have used various age groups although this review focused only on adult populations, whereas some countries have included older adolescents $[18,20,49]$ and the elderly for prevalence studies $[14,18,21]$. The inclusion of younger individuals and also older adults may lead to underestimates of the prevalence of obesity in adults. Similarly, in some countries, prevalence data were restricted to one gender [25], a specific area of residence [50] and a single time point [13], each of which limits interpretation of the general obesity prevalence and trends in the region. Prospective studies are needed to identify the incidence of the obesity in the whole region. 
Jayawardena et al.: Prevalence, Trends and Associated Socio-Economic Factors of Obesity in South Asia

\section{Conclusion}

It is evident that overweight and obesity have already reached epidemic proportions in South Asian countries, and, based on current trends, the longer-term prognosis is even more threatening. The widespread use of more appropriate lower anthropometric cut-offs may further increase current estimates. Furthermore, obesity in South Asia has a unique cluster of associated socio-economic factors. Immediate action is required in both prevention and management by engaging healthcare workers, policy makers and educators before overweight and obesity levels achieve more alarming proportions.

\section{Acknowledgements}

We are grateful to Mr Peter Sondergeld, who helped us in literature searching.

\section{Disclosure Statement}

The authors declare no conflict of interest.

\section{References}

1 WHO: Obesity and overweight; in WHO (ed): Global Strategy on Diet, Physical Activity and Health. Geneva WHO, 2010. www.who.int/dietphysicalactivity/strategy/eb11344/strategy_english_web.pdf.

$\checkmark 2$ Caballero B: The global epidemic of obesity: an overview. Epidemiol Rev 2007;29:1-5.

3 McLaren L: Socioeconomic status and obesity. Epidemiol Rev 2007;29:29-48.

$\rightarrow 4$ Snyder JD, Merson MH: The magnitude of the global problem of acute diarrhoeal disease: A review of active surveillance data. Bull World Health Organ 1982;60:605-613.

5 Muller O, Krawinkel M: Malnutrition and health in developing countries. Can Med Assoc J 2005;173:279-286.

-6 Misra A, Khurana L: Obesity-related non-communicable diseases: South Asians vs white Caucasians. Int J Obes (Lond) 2010;35:167-187.

7 Ghaffar A, Reddy K, Singhi M: Burden of non-communicable diseases in South Asia. BMJ 2004;328:807-810.

8 The Central Intelligence Agency: The World Factbook: South Asia, 2010. www.cia.gov/library/publications/ the-world-factbook/.

-9 Yoon K, Lee J, Kim J, Cho J, Choi Y, Ko S, Zimmet P, Son H: Epidemic obesity and type 2 diabetes in Asia. Lancet 2006;368:1681-1688.

10 Sharma M: Designing effective health education interventions for preventing obesity in South Asian Americans. Calif J Health Promot 2006;4:119-128.

11 SAARC: South Asian Association for Regional Cooperation. http://www.saarc-sec.org/.

12 Ahmed S, Lemkau J: Cultural issues in the primary care of South Asians. J Immigr Health 2000;2:89-96.

13 Aboobakur M, Latheef A, Mohamed A, Moosa S, Pandey R, Krishnan A, Prabhakaran D: Surveillance for noncommunicable disease risk factors in maldives: results from the first steps survey in male. Int J Public Health 2010;55:489-496.

14 Katulanda P, Jayawardena MA, Sheriff MH, Constantine GR, Matthews DR: Prevalence of overweight and obesity in Sri Lankan adults. Obes Rev 2010;11:751-756.

-15 Sharma SK, Ghimire A, Radhakrishnan J, Thapa L, Shrestha NR, Paudel N, Gurung K, R M, Budathoki A, Baral N, Brodie D: Prevalence of hypertension, obesity, diabetes, and metabolic syndrome in Nepal. Int J Hypertens 2011;2011:821971.

16 Shafique S, Akhter N, Stallkamp G, de Pee S, Panagides D, Bloem MW: Trends of under- and overweight among rural and urban poor women indicate the double burden of malnutrition in Bangladesh. Int J Epidemiol 2007; 36:449-457.

17 Razzaque A, Nahar L, Van Minh H, Ng N, Juvekar S, Ashraf A, Ahmed SM, Soonthornthada K, Kanungsukkasem U, Huu Bich T: Social factors and overweight: Evidence from nine Asian INDEPTH Network sites. Glob Health Action 2009;2. doi: 10.3402/gha.v2i0.1991.

18 Jafar TH, Chaturvedi N, Pappas G: Prevalence of overweight and obesity and their association with hypertension and diabetes mellitus in an Indo-Asian population. CMAJ 2006;175:1071-1077.

19 Shah S, Hussain A, Jafar T, Reeder B: Obesity in a South Asian population: trends between 1995 and 2007. Obes Rev 2010;11:59.

20 IIPS and Macro International: National Family Health Survey (NFHS-3), 2005-06:India; in Sciences IIfP (ed). Mumbai, 2007. 


\begin{tabular}{l|l}
\hline \multicolumn{2}{l}{ Obes Facts 2013;6:405-414 } \\
\hline DOI: $10.1159 / 000355598$ & $\begin{array}{l}\text { C 2013 S. Karger GmbH, Freiburg } \\
\text { www.karger.com/ofa }\end{array}$ \\
\hline
\end{tabular}

Jayawardena et al.: Prevalence, Trends and Associated Socio-Economic Factors of Obesity in South Asia

21 Deepa M, Farooq S, Deepa R, Manjula D, Mohan V: Prevalence and significance of generalized and central body obesity in an urban Asian Indian population in Chennai, India (cures: 47). Eur J Clin Nutr 2009;63:259-267.

22 Mohan V, Mathur P, Deepa R, Deepa M, Shukla DK, Menon GR, Anand K, Desai NG, Joshi PP, Mahanta J, Thankappan KR, Shah B: Urban rural differences in prevalence of self-reported diabetes in India - the WHO-ICMR Indian NCD risk factor surveillance. Diabetes Res Clin Pract 2008;80:159-168.

23 Fernando D, Siribaddana S, De Silva D: Impaired glucose tolerance and diabetes mellitus in a suburban Sri Lankan community. BMJ 1994;70:347.

24 Malavige G, de Alwis N, Weerasooriya N, Fernando D, Siribaddana S: Increasing diabetes and vascular risk factors in a sub-urban Sri Lankan population. Diabetes Res Clin Pract 2002;57:143-145.

25 Balarajan Y, Villamor E: Nationally representative surveys show recent increases in the prevalence of overweight and obesity among women of reproductive age in Bangladesh, Nepal, and India. J Nutr 2009;139: 2139-2144.

26 National Nutrition Monitoring Bureau (NNMB): Diet and nutritional status of rural population; in Bureau NNM (ed): NNMB Technical Report 2002.

27 National Nutrition Monitoring Bureau (NNMB): Diet and nutritional status of population and prevalence of hypertension amongst adults in rural areas.; in Bureau NNM (ed): NNMB Technical Report, 2007.

-28 Singh RB, Pella D, Mechirova V, Kartikey K, Demeester F, Tomar RS, Beegom R, Mehta AS, Gupta SB, De Amit K, Neki NS, Haque M, Nayse J, Singh S, Thakur AS, Rastogi SS, Singh K, Krishna A: Prevalence of obesity, physical inactivity and undernutrition, a triple burden of diseases during transition in a developing economy. The Five City Study Group. Acta Cardiol 2007;62:119-127.

29 Wang Y, Chen HJ, Shaikh S, Mathur P: Is obesity becoming a public health problem in India? Examine the shift from under- to overnutrition problems over time. Obes Rev 2009;10:456-474.

30 Yajnik CS: Obesity epidemic in India: intrauterine origins? Proc Nutr Soc 2004;63:387-396.

-31 Subramanian SV, Kawachi I, Smith GD: Income inequality and the double burden of under- and overnutrition in India. J Epidemiol Commun Health 2007;61:802-809.

32 Ghosh A: Effects of socio-economic and behavioural characteristics in explaining central obesity - a study on adult Asian Indians in Calcutta, India. Coll Antropol 2006;30:265-271.

33 Balkau B, Deanfield J, Després J, Bassand J, Fox K, Smith Jr S, Barter P, Tan C, Van Gaal L, Wittchen H: International Day for the Evaluation of Abdominal Obesity (IDEA): a study of waist circumference, cardiovascular disease, and diabetes mellitus in 168000 primary care patients in 63 countries. Circulation 2007;116:19421951.

-34 WHO Expert Consultation: Appropriate body-mass index for Asian populations and its implications for policy and intervention strategies. Lancet 2004;363:157-163.

35 WHO: Obesity: Preventing and managing the global epidemic. Report of a WHO consultation. World Health Organ Tech Rep Ser 2000;894:i-xii, 1-253.

-36 Misra A, Vikram N, Gupta R, Pandey R, Wasir J, Gupta V: Waist circumference cutoff points and action levels for Asian Indians for identification of abdominal obesity. Int J Obes (Lond) 2005;30:106-111.

-37 Katulanda P, Jayawardena MA, Sheriff MH, Matthews DR: Derivation of anthropometric cut-off levels to define CVD risk in Sri Lankan adults. Br J Nutr 2011;105:1084-1090.

-38 Misra A, Chowbey P, Makkar BM, Vikram NK, Wasir JS, Chadha D, Joshi SR, Sadikot S, Gupta R, Gulati S, Munjal YP: Consensus statement for diagnosis of obesity, abdominal obesity and the metabolic syndrome for Asian Indians and recommendations for physical activity, medical and surgical management. J Assoc Physicians India 2009;57:163-170.

39 Deurenberg-Yap M, Schmidt G, Van Staveren W, Deurenberg P: The paradox of low body mass index and high body fat percentage among Chinese, Malays and Indians in Singapore. Int J Obes (Lond) 2000;24:1011-1017.

40 Razak F, Anand S, Shannon H, Vuksan V, Davis B, Jacobs R, Teo K, McQueen M, Yusuf S: Defining obesity cut points in a multiethnic population. Circulation 2007;115:2111-2118.

41 Illangasekera U, Rambodagalla S, Tennakoon S: Temporal trends in the prevalence of diabetes mellitus in a rural community in Sri Lanka. J R Soc Promot Health 2004;124:92-94.

-42 Jayawardena R, Byrne NM, Soares MJ, Katulanda P, Hills AP: Consumption of Sri Lankan adults: an appraisal of serving characteristics. Public Health Nutr 2013;16:653-658.

43 Flegal K, Carroll M, Ogden C, Curtin L: Prevalence and trends in obesity among US adults, 1999-2008. JAMA 2010;303:235-241.

44 Asia Pacific Cohort Studies Collaboration: The burden of overweight and obesity in the Asia-Pacific region. Obes Rev 2007;8:191-196.

45 Rennie KL, Jebb SA: Prevalence of obesity in Great Britain. Obes Rev 2005;6:11-12.

46 Zaman MM, Yoshiike N: Prevalence of overweight defined by body mass index in a rural adult population of Bangladesh. J Health Popul Nutr 2003;21:162-163.

47 Garg C, Khan SA, Ansari SH, Garg M: Prevalence of obesity in Indian women. Obes Rev 2010;11:105-108.

48 Jayawardena R, Ranasinghe P, Byrne N, Soares M, Katulanda P, Hills A: Prevalence and trends of the diabetes epidemic in South Asia: a systematic review and meta-analysis. BMC Public Health 2012;12:380.

49 Khan MMH, Kraemer A: Factors associated with being underweight, overweight and obese among evermarried non-pregnant urban women in Bangladesh. Singapore Med J 2009;50:804-813.

50 Vaidya AK, Pokharel PK, Nagesh S, Karki P, Kumar S, Majhi S: Association of obesity and physical activity in adult males of Dharan, Nepal. Kathmandu Univ Med J 2006;4:192-197. 